\title{
Antibacterial and Toxicity Activities of Streptosporangium sp. SM1P
}

\author{
Risa Nofiani*, Rizky, Ridho Brilliantoro \\ Department of Chemistry, Faculty of Mathematics and Natural Sciences, Tanjungpura University, \\ Jl. Prof. Dr. H. Hadari Nawawi, Pontianak, Indonesia, 78124 \\ *Corresponding author email: risa.nofiani@chemistry.untan.ac.id and rnofiani@yahoo.com
}

Received May 03, 2021; Accepted August 05, 2021 ; Available online November 15, 2021

\begin{abstract}
Multidrug resistance in pathogenic microorganisms and cancer cell has encouraged to search for novel antibiotics and cancer drugs from many sources such as actinobacteria. This study aims to characterize and evaluate the antibacterial and toxicity activities from an actinobacterium isolated from mangrove mud sample, Mempawah District, West Kalimantan. The mangrove mud sample was inoculated on ISP4 agar using a pour plate method and purified to obtain a pure isolate. The pure isolate was characterized by morphological and biochemical traits and screened antibacterial and toxicity activities. The antibacterial activities were evaluated at different media (ISP1 agar, ISP1 broth, and ISP4 agar) and the state fermentation (solid-state fermentation (SSF), liquid state fermentation (LSF). Two suspected actinobacterial colonies were successfully isolated and one isolate was characterized as a genus of Streptroporangium, then called Streptroporangium sp. SMIP. Streptroporangium sp. SMIP showed antibacterial activities on both ISPI agar (Streptococcus mutants and Salmonella typhi ) and ISP4 agar (S. mutants, Escherichia coli, Vibrio cholerae, Staphylococcus aureus and S. typhi) using the cross-streak method for the SSF. The extract Streptroporangium sp. SMIP was also active against 2 of the test bacteria (S. mutants and E. coli) using the well-diffusion method for the LSF. The best medium and state fermentation for antibacterial activities were ISP4 agar with the SSF. The extract Streptroporangium sp.SMIP prepared on ISPI broth showed toxic activity based on $\mathrm{LC}_{50}(106.09 \mu \mathrm{g} / \mathrm{mL})$. Therefore, Streptroporangium sp. SMIP can be used as a new potential source for exploring secondary metabolites, particularly antibacterial and toxicity activities.
\end{abstract}

Keywords: antibacterial, toxicity, Streptosporangium, solid-state fermentation, liquid-state fermentation

\section{INTRODUCTION}

Actinobacteria or actinomycetes are Gram-positive bacteria that have high $\mathrm{G}+\mathrm{C}$ content. Many members of the genus actinobacteria can produce various secondary metabolites having broad range biological activities, such as antimicrobial, antitumour, antiparasitic and immunosuppressive activities. This phylum has received more attention from most researchers that focus on exploring secondary metabolites, particularly from Streptomyces sp. genera. Streptomyces sp. is the most antibiotic producer in the market, such as erythromycin and streptomycin (Salwan \& Sharma, 2020). Streptomyces $\mathrm{sp}$. has been continually explored secondary metabolites by scientists, which often causes reisolation of known secondary metabolites. Lately, most scientists use rare actinobacteria as secondary metabolite producers to avoid re-isolation of known secondary metabolites. Rare actinobacteria are categorized if actinobacteria abundance are lower than Streptomyces abundance such as Streptosporangium sp. Micromonospora sp. Nocardia sp. Salinospora sp. Pseudonocardia sp. etc (Benhadi, Gacemi-Kirane, Menasria, Guebla, \& Ahmane, 2019; Mullowney et al., 2015). Rare actinobacteria are also reported by scientists producing novel secondary metabolites with various biological activities (Azman, Othman, Velu, Chan, \& Lee, 2015). Streptosporangium amethystogenes BCC 27081 produces new secondary metabolites such as amethysione (weak cytotoxic activity) and amethysamide (Boonlarppradab, Suriyachadkun, Supothina, \& Laksanacharoen, 2016). Micromonospora zhangzhouensis sp. nov isolated from mangrove soil produces a new diterpenoid showing cytotoxic activities (Fu et al., 2020). Nocardia sp. PB-52 and Nocardia sp. produce antimicrobial and cytotoxic compounds, respectively (Sharma, Priyanka, Kalita, \& Thakur, 2016; Noël, van Soen, Rouaud, Hitti, \& Tomasi, 2020). Salinospora tropica produces various secondary metabolites with antimicrobial, anti-tumour and cytotoxic activities (Fu et al., 2020). Pseudonocardia sp. JB05 was reported to produce antibacterial compounds against Staphylococcus aureus (Jafari, Behroozi, Farajzadeh, Farsi, \& Akbari-Noghabi, 2014).

One strain microorganism usually contains many compounds or secondary metabolites or is known as One Strain Many Compounds (OSMAC) (Romano, Jackson, Patry, \& Dobson, 2018). The secondary 
metabolite is coded by a set of secondary metabolite biosynthetic gene clusters (SMBGCs). The SMBGCs can not always be expressed every time to produce a secondary metabolite and is called a silent secondary metabolite BGC. For example, Streptosporangium sp. CGMCC 4.7309 is reported to contain 20 silent SMBGCs based on the genome data, but not all produce secondary metabolites simultaneouly (Ding, Yang, Zhang, \& Shen, 2019).

Silent SMBGCs may be caused by various factors such as fermentation conditions and growth medium. Therefore, activating the silent SMBGCs can be conducted by cultivating microorganisms with different media and state fermentation, besides increasing titer secondary metabolites. For the medium, Streptomyces sp. RC5 shows antibacterial activities on AM media, but no modified Bennet dissolved in artificial water (ASW) and ISP1+the trace element dissolved in ASW (Nofiani et al., 2020). Vibrio coralliilyticus produces an antibiotic andrimid when the medium uses chitin and macroalgal extracts as sole nutrient sources (Wietz, Månsson, M, \& Gram, 2011). E-rhodomycinone isolated from Streptosporangium sp. NN 22302 increases 2 -fold when the agitation is increased from $500 \mathrm{rpm}$ to $700 \mathrm{rpm}$ (Pfefferle, Theobald, Gürtler, \& Fiedler, 2000). For fermentation conditions, the actinobacteria producing melanin pigment is higher yield in the liquid-state fermentation (LSF) than the solid-state fermentation (SSF) (Sharma et al., 2018). The SSF uses solid substrate with a low water level, while the LSF uses liquid substrate.

Mangrove forest is a unique ecosystem due to high salinity, high temperature, muddiness, nutrition availability and high temperature (Arumugam, Kumar, Hemavathy, Swetha, \& Karishma 2018). Interactions among microorganisms, biotic (such as coral) and abiotic (environment) can activate microorganisms to produce various secondary metabolites. Exploration of rare actinobacteria from a unique ecosystem can probably increase the discovery of novel secondary metabolites for drug discovery, notably novel antibacterial or antitumour compounds. It can overcome multidrug resistance in pathogenic microorganisms and cancer treatment that has been becoming a global healthcare problem. In this study, we isolated actinobacteria from the unique mangrove ecosystem. This research aims to characterize and evaluate the antibacterial and toxicity activities from actinobacteria isolated from the mangrove mud, Mempawah District, West Kalimantan.

\section{EXPERIMENTAL SECTION \\ Materials}

Media used in this study were ISPI (International Streptomyces Project 1), ISP4 (International Streptomyces Project 4), NA (Nutrient Agar), LB (LuriaBertani), phenol red base broth, sulphite indole motility (SIM), Simmons citrate agar, skim milk, corn starch, $\mathrm{D}(+)$-glucose, $\mathrm{D}(+)$-sucrose, $\mathrm{D}(-)$-mannitol, and MR-VP. Chemical reagents used in this study were pro analysis grade, namely meropenem $\left(\mathrm{C}_{17} \mathrm{H}_{25} \mathrm{~N}_{3} \mathrm{O}_{5} \mathrm{~S}\right)$, nystatin $\left(\mathrm{C}_{47} \mathrm{H}_{74} \mathrm{NO}_{17}\right)$, tetracycline $\left(\mathrm{C}_{22} \mathrm{H}_{24} \mathrm{~N}_{2} \mathrm{O}_{8}\right)$, ethyl acetate $\left(\mathrm{C}_{4} \mathrm{H}_{8} \mathrm{O}_{2}\right)$, seawater, immersion oil, Gram-staining kit, $\mathrm{NaCl}, \mathrm{H}_{2} \mathrm{O}_{2}$, tetramethyl-p-phenylene-diamine dihydrochloride, methyl red, $\alpha$-naphthol, $\mathrm{KOH}$. Artemia salina eggs used in this study were the Supreme Plus brand. The test bacteria were used in this study as follows: S. aureus, Salmonella typhi, Escherichia coli, Pseudomonas aeruginosa, Vibrio cholera, and Streptococcus mutants.

\section{Sampling}

A sample of mangrove mud was collected from the Mangrove Park, Mempawah District, in September 2019. The sample was taken at a depth of $15 \mathrm{~cm}$ with coordinate N 023'49.812" E 108'56'44.2068".

\section{Isolation of Actinomycetes}

One gram of the sample was suspended with $9 \mathrm{~mL}$ of sterilized them vortexed $3 \times 10 \mathrm{~s}$. One $\mathrm{mL}$ of suspension sample was inoculated using the pour plate method into a ISP4 agar media enriched meropenem $(75 \mu \mathrm{g} / \mathrm{mL})$ and nystatin $(100 \mu \mathrm{g} / \mathrm{mL})$. The colony growth on surface media was observed every day for a month. A powdery or wrinkle or dull colony was a positive colony for actinomycetes. The suspected colony was purified by transferring into a new ISP4 agar to get a pure isolate.

\section{Characterization of the Isolate}

The isolate was characterized by morphological and biochemical features based on $\mathrm{Li}$ et al. (Li, Chen, Jiang, \& Jiang, 2016a). The morphological traits of the isolate were observed as follows: both cellular (cell shape, spore, sporangia, sporangiospore) and colonial characters (shape and size, colour, dimensions, form, motility, diffusible and melanoid pigment). The biochemical traits of the isolate were determined as follows: on $\mathrm{NaCl}$ tolerance, $\mathrm{pH}$ tolerance, carbohydrate fermentation tests $(D(+)$ glucose, $D(-)$-mannitol, $D(+)$-sucrose fermentation tests), enzyme characteristic tests (protein hydrolysis test, starch hydrolysis, catalase test, oxidase test, decarboxylate lysine test), metabolite products (IMViC tests (indole test, methyl red test, Vorges-Proskaues test, citrate utilization test) and hydrogen sulfide $\left(\mathrm{H}_{2} \mathrm{~S}\right)$ production test).

The morphological spore of the isolate was examined using slide culture methods. The slide culture was carried out by inoculating the isolate on ISP1 agar media sized $5 \mathrm{~mm}^{2}$, then putting it on a sterile slide and covered with a sterile coverslip, then incubated at room temperature. The observation of spore and mycelium was carried out under a light microscope with $100 \times$ magnification on day $7,14,21$, 28 , and 30 . The morphological isolate was also examined using Gram staining. The procedure of the Gram staining was carried based on the manufacturing guidelines. The spore colour, diffusible 
and melanoid pigment was evaluated by inoculating the isolate on various media (ISP1, ISP2, ISP3, and ISP4) then incubated at room temperature for 3-21 days. The spore colour was observed on the colony surface. The diffusible pigment was observed in its colour on the reverse side colony and called distinctive (+) for red, yellow, green, blue, or violet and not distinctive (-) for pale yellow, olive, or yellowish-brown. Greenish brown, brownish-black on the medium surface was recorded as a positive melanoid pigment. Melanoid pigment was negative if it was out of greenish-brown, brownish-black colour on the medium surface.

$\mathrm{NaCl}$ tolerance, the isolate was tested on ISPI agar supplemented with various $\mathrm{NaCl}$, namely: $0 \%, 2.5 \%$, $5 \%, 7.5 \%, 10 \%$ and $12.5 \%$ and incubated at room temperature for 3-21 days to observe the colony growth. $\mathrm{pH}$ tolerance, the isolate was streaked on ISP 1 agar with various $\mathrm{pH}$, namely: $4,5,8,9,10,11$ and 12, respectively. Each plate was incubated at room temperature for 3-12 days to observe the colony growth.

The carbohydrate fermentation tests for $D(+)$ glucose, sucrose, and $\mathrm{D}(+)$-mannitol were carried out on phenol red base broth added with $1 \% D(+)$ glucose, $\mathrm{D}(+)$-mannitol, $\mathrm{D}(+)$-sucrose, $1 \%$ sucrose, and $1 \%$ of $\mathrm{D}(+)$-mannitol, respectively. The medium in a tube was provided with a Durham tube. Each isolate was inoculated and incubated at room temperature for 3-4 days. The culture colour changed from red to yellow for the positive test result. If no colour change, it was concluded as a negative test result.

One inoculating loop of the isolate was inoculated on ISP2 agar supplemented with $1 \%$ of corn starch and incubated for 3-4 days. The positive test for starch hydrolysis was signed with a clear zone around the colony. The isolate was inoculated on ISP2 agar supplemented with $1 \%$ of skim milk and incubated for 3-4 days. The positive test for protein hydrolysis was signed with a clear zone around the colony. One inoculating loop of the isolate was inoculated on urea broth and incubated at room temperature for 3-4 days. The media colour was changed from yellow to pink-red and recorded as a positive urease test. One inoculating loop of the isolate was mixed with a drop of water put on a slide, then added one or two drops $3 \%$ of hydrogen peroxide $\left(\mathrm{H}_{2} \mathrm{O}_{2}\right)$. The negative or positive catalase test produced without or air bubbles, respectively. The strip of Whatman's No. 1 filter paper was wetted with ten drops of fresh $1 \%$ of tetramethylp-phenylene-diamine dihydrochloride than one inoculating loop of the isolate was directly streaked on the strip. A positive oxidase test indicated a deeppurple hue in the media around the colony. One inoculating loop was streaked on a lysine iron agar slant and incubated at room temperature for 3-4 days. The positive result for the lysine decarboxylation test was formed violet colour on media. The negative result was no violet on media.
Motility and $\mathrm{H}_{2} \mathrm{~S}$ production tests were carried out on sulphide indole motility (SIM) medium. The isolate was inoculated by means of stab inoculation on SIM medium and incubated at room temperature for 3-4 days. The positive motility gave a diffuse spreading growth around the colony. A black precipitate in SIM medium was concluded as a positive in $\mathrm{H}_{2} \mathrm{~S}$ production. Otherwise, no black precipitation indicated a negative $\mathrm{H}_{2} \mathrm{~S}$ production. One inoculating loop was inoculated on Simmons citrate slant agar and incubated at room temperature for 3-4 days. A positive citrate utilization test observed the development from green colour to blue colour.

The methyl red (MR) and Voges Proskauer (VP) test were carried out by inoculating one inoculating loop of the isolate on $3 \mathrm{~mL}$ of MR-VP medium. After 4 days of incubation, the culture was added a drop of methyl red reagent $(0.25 \mathrm{~g}$ of methyl red dissolved in $100 \mathrm{~mL}$ of ethanol) for the MR test. Red and red-orange cultures were recorded as positive and weak positive MR test, respectively, while yellow or orange colour indicated a negative MR test. For the VP test, the culture incubated at room temperature for 4 days was mixed $0.6 \mathrm{~mL}$ of reagent $\mathrm{A}(5.0 \mathrm{~g}$ of $\alpha$-naphthol in $100 \mathrm{ml}$ of absolute (100\%) ethanol) and then mixed with $0.2 \mathrm{~mL}$ of reagent $B(40.0 \mathrm{~g}$ of $\mathrm{KOH}$ in $100 \mathrm{ml}$ of distilled water). The positive reaction gained a strong cherry red colour at the surface of the medium after incubation for 15-60 min.

\section{Antibacterial Activities Using Cross Streak Method for the SSF}

Antibacterial activities for the SSF were conducted using a cross streak method (Williston, Zia-Walrath, \& Youmans, 1947). The isolate was inoculated by making a straight line in the middle of the media. After 6 days of incubation, each test bacteria was inoculated by scratching the left and right sides of the isolate and incubated at room temperature for 3 - 5 days. A clear zone between the isolate and a bacterial test showed a positive test. The inoculating loop was touched on the clear zone, then streaked on a NA medium. After 12-16 hours of incubation time at room temperature, the colony growing on the NA medium was observed to check bacteriostatic or bactericidal activities. If the colony appeared on the media surface, it was called bacteriostatic activity. If no colony, it was known to have bactericidal activity.

\section{Production and Extraction of the Isolate}

The seed culture of the isolate was prepared by inoculating $1 \mathrm{~cm}^{2}$ of the spore into $20 \mathrm{~mL}$ of ISP1 broth and shaken at $200 \mathrm{rpm}$ and room temperature. After 3 days, $2 \mathrm{~mL}$ of the seed culture was inoculated on $100 \mathrm{~mL}$ of ISP1 broth (Erlenmeyer $500 \mathrm{~mL}$ ) and shaken at $200 \mathrm{rpm}$ and room temperature for 10 days. Then, the culture was centrifuged at 1,048 $\times \mathrm{g}$ for $40 \mathrm{~min}$ and obtained supernatant and cell. The supernatant was extracted using ethyl acetate with a 
ratio 1:1 for supernatant and ethyl acetate for 3 times. All of the organic layers were combined and evaporated using a rotary evaporator to gain the extract.

\section{Antibacterial Activities Using Well Diffusion Method for the LSF}

An inoculating loop of each test bacteria (S. aureus, S. typhi, E. coli, P. aeruginosa, V. cholera, and $S$. mutants) was inoculated on Luria-Bertani (LB) broth and shaken at $200 \mathrm{rpm}$, room temperature. After 12 14 hours of incubation, the bacterial test culture was harvested and used for the antibacterial assay.

Antibacterial assay was conducted using the well diffusion method (Nofiani et al., 2020). A $1.000 \mu \mathrm{L}$ of each bacterial test culture was mixed with $22.5 \mathrm{~mL}$ of warm LB agar media and poured on a petri dish with $10 \mathrm{~cm}$ of diameter. After solid, the medium was punched using a sterile puncher with $6 \mathrm{~mm}$ of diameter. A $20 \mu \mathrm{L}(750 \mu \mathrm{g})$ of the extract was dispensed to the well and let the solvent in the extract evaporated, then incubated at room temperature for a day. Tetracycline $(10 \mu \mathrm{g} /$ well) and ethyl acetate were also injected into the well and used as the positive and negative control, respectively. The positive antibacterial activities were signed by formed a clear zone around the well. The diameter of the clear zone was measured using a vernier calliper.

Toxicity Assay Using Brine Shrimp Lethality Test (BSLT)

Toxicity assay was carried out using BSLT procedure (Meyer et al., 1982). Brine shrimp eggs, $A$. salina, were hatched with seawater and incubated at room temperature for 2 days. After the eggs hatch out, ten nauplii were collected by pipette and transferred in a small vial containing $700 \mu \mathrm{L}$ of seawater then added $20 \mu \mathrm{L}$ of the crude extract with various concentration $(200 \mu \mathrm{g} / \mathrm{mL}, 100 \mu \mathrm{g} / \mathrm{mL}, 50 \mu \mathrm{g} / \mathrm{mL}, 25 \mu \mathrm{g} / \mathrm{mL}, 12.5$ $\mu \mathrm{g} / \mathrm{mL}, 6 \mu \mathrm{g} / \mathrm{mL}, 3.125 \mu \mathrm{g} / \mathrm{mL}$ and $0 \mu \mathrm{g} / \mathrm{mL}$ ). Finally, the vial was added seawater until $1 \mathrm{~mL}$ and incubated at room temperature. After 24 hours, the survivors were counted with the aid of a magnifying glass. The percentage death at each dose and control (without the crude extract) was calculated as follows: \% deaths $=[($ test-control $) /$ control $] \times 100 \%$. The test was carried out in quadruplicate. Lethal concentration 50\% $\left(\mathrm{LC}_{50}\right)$ was calculated using probit analysis with IBM SPSS statistic 23.

\section{RESULTS AND DISCUSSION}

\section{Isolation and Characterization of the Isolate}

SMIP was one of two isolates that appeared on day four at the surface of ISP4 agar supplemented with meropenem and nystatin. A small powdery colony, SMIP, was suspected as an actinobacterial characteristic that was rich in secondary metabolites with various biological activities. SMIP showed as a fast-growth colony compared to the other actinobacteria in this isolation step. Therefore, SMIP was further characterized to determine its genus and biological activities.

SMIP was characterized by morphological and biochemical features based on $\mathrm{Li}$ et al. (Li, Chen, Jiang, \& Jiang, 2016b). SM1P exhibited compact, tough and dull colony morphology on the ISP1, ISP2, ISP3, and ISP4 agar media (Figure 1A, yellow arrow). White spore SMIP started to appear on day 4 for ISP1 agar, ISP2 agar, and ISP4 agar, while day 14 for ISP3 agar. SMIP did not produce melanoid and produced dark pink diffusible pigment on ISP4 agar (Figure 1C, Table 1). The morphological colony and spore were similar to the actinobacterial colony and spore. The morphological appearance of the actinobacterial colony is characterized as compact, tough, dull, and often leathery or wrinkle. Some actinobacterial colonies are dry colony surfaces on culture media and frequently covered with aerial mycelium and spore. Gram staining SMIP showed Gram-positive branched hyphae which formed purple hyphae (Figure 1D).

Sporangiospore SMIP prepared with a slide culture method with 21 day old was observed under a light microscope with $100 \times$ magnification. SM1P sporangiospores gained an irregular shape or ovalshape (Figure 2). The sporangia were born by fragmented mycelia. The sporangiospore of SMIP was similar to that of Streptosporangium. Characteristics of Streptosporangium sp. generally bear sporangia on their aerial mycelia produced with or without fragmentation of hyphae within its sheath (Williams \& Sharples, 1976; Boudiella et al., 2007). The expanded sheath of streptosporangium is obtained from coiling of the sporogenous hyphae. This sheat forms the sporangial Streptosporangium sp. Most spores in sporangiospores are irregular shape or rod-shaped, or oval-shaped and variable in size (Williams \& Sharples, 1976; L. Zhang, Jiang, \& Chen, 2002). Streptosporangium is an actinobacterial genera classified based on its sporangial morphology (Hazarika \& Thakur, 2020). Morphological characteristics notably colony and sporangiospores SMIP close to Streptosporangium based on $\mathrm{Li}$ et al. (2016b), Williams \& Sharples (1976), and Zhang et al. (2002) (Figure 2). Therefore. SMIP could be identified as Streptosporangium and called Streptosporangium sp. SM1P. The biochemical characteristic of Streptosporangium sp. SM1P was $\mathrm{NaCl}$ tolerance between $0 \%$ and $7.5 \%$ of $\mathrm{NaCl}$. It was categorized as moderate halophilic actinobacteria. However, $\mathrm{NaCl}$ tolerance of $7.5 \%$ was the best $\mathrm{NaCl}$ for optimal growth Streptosporangium sp. SM 1 P. The $\mathrm{pH}$ tolerance of Streptosporangium sp. SMIP was from 5 to 10 and categorized as alkaliphilic actinobacteria. The biochemical test of Streptosporangium sp. SMIP only showed positive tests for decarboxylase lysine and catalase (Table 1). Streptosporangium sp. SM1P showed a positive test for three of four IMViC tests, namely indole, methyl red and Voges-Proskauer. 
Table 1. Morphological and biochemical characteristics of SM1P

\begin{tabular}{|c|c|c|c|}
\hline Tests & Results & Tests & Results \\
\hline Morphology & & $\mathrm{pH}$ Tolerance & \\
\hline Gram staining & + & $\mathrm{pH} 4.0$ & - \\
\hline \multirow[t]{2}{*}{ Motil } & - & $\mathrm{pH} 5.0$ & + \\
\hline & & $\mathrm{pH} 8.0$ & + \\
\hline Spore mass colour & & $\mathrm{pH} 9.0$ & + \\
\hline ISPI & white & $\mathrm{pH} 10.0$ & \pm \\
\hline ISP2 & white & $\mathrm{pH} 11.0$ & - \\
\hline ISP3 & white & $\mathrm{pH} 12.0$ & - \\
\hline \multirow[t]{2}{*}{ ISP4 } & white & & \\
\hline & & Carbohydrate fermentations & \\
\hline \multirow{2}{*}{\multicolumn{2}{|c|}{ Diffusible pigment }} & & \\
\hline & & $\mathrm{D}(+)$-glucose & - \\
\hline ISP1 & nd & $D(-)-M a n n i t o l$ & + \\
\hline ISP2 & nd & Sucrose & - \\
\hline ISP3 & nd & & \\
\hline ISP4 & d, dark pink & Enzyme characteristic tests & \\
\hline \multirow{2}{*}{\multicolumn{2}{|c|}{ Melanoid Pigmentation }} & Protease hydrolysis & - \\
\hline & & Starch hydrolysis & - \\
\hline ISP1 & - & Urease & - \\
\hline ISP2 & - & Katalase & + \\
\hline ISP3 & - & Oxidase & - \\
\hline ISP4 & - & Lysine decarboxylase & + \\
\hline $\mathrm{NaCl}$ tolerance & & Metabolite products & \\
\hline $0 \%(w / v) \mathrm{NaCl}$ & + & $\mathrm{H}_{2} \mathrm{~S}$ production & - \\
\hline $2.5 \%(\mathrm{w} / \mathrm{v}) \mathrm{NaCl}$ & + & $\begin{array}{l}\text { Indol/ tryptophan } \\
\text { decomposition }\end{array}$ & + \\
\hline $5 \%(\mathrm{w} / \mathrm{v}) \mathrm{NaCl}$ & + & Methyl red & + \\
\hline $7.5 \%(\mathrm{w} / \mathrm{v}) \mathrm{NaCl}$ & \pm & Voges Proskauer & + \\
\hline $10 \%(w / v) \mathrm{NaCl}$ & - & Simon citrate & - \\
\hline $12.5 \%(\mathrm{w} / \mathrm{v}) \mathrm{NaCl}$ & - & & \\
\hline $\mathrm{NaCl}$ optimum & $2.5 \%$ & & \\
\hline
\end{tabular}

+: positive test/growth; -: negative test/growth. \pm . less growth. $d$ : distinctive. nd: not distinctive. Sign for melanoid pigment: +: produced pigment; -: no produced pigment.

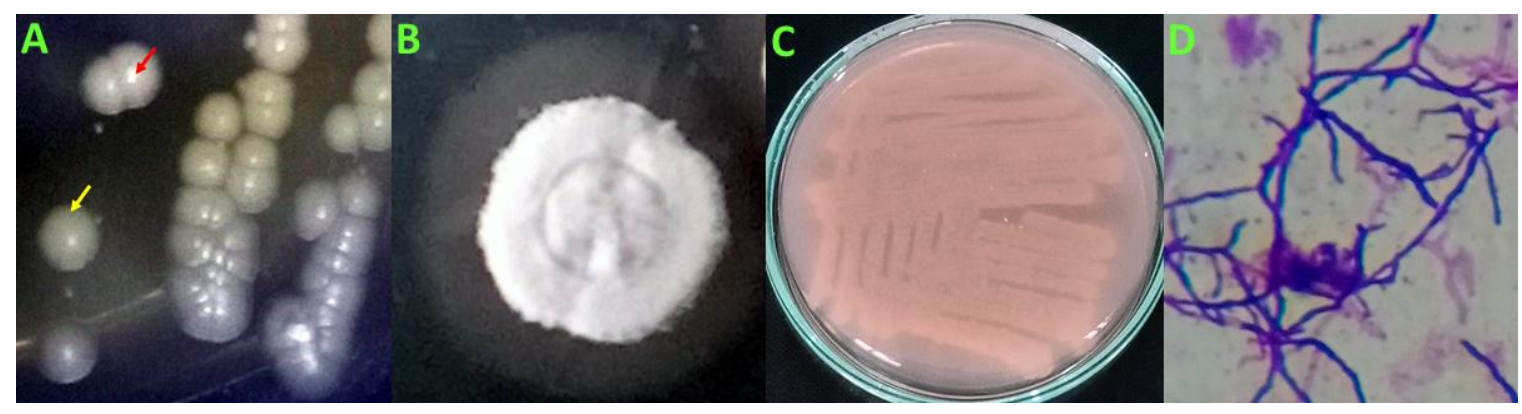

Figure 1. Morphological colony and hyphae of SM1P. A. Dull and tough colony SMIP on ISP2 agar. B. Mycelial colony SM1P covered by white spore on ISP1 agar C. Distinctive diffusible pigment SM IP on ISP4 agar. D. Branched hyphae SM1P stained with the Gram staining. Yellow arrow: mycelial colony SM1P. Red arrow. White spore-bearing mycelia. 

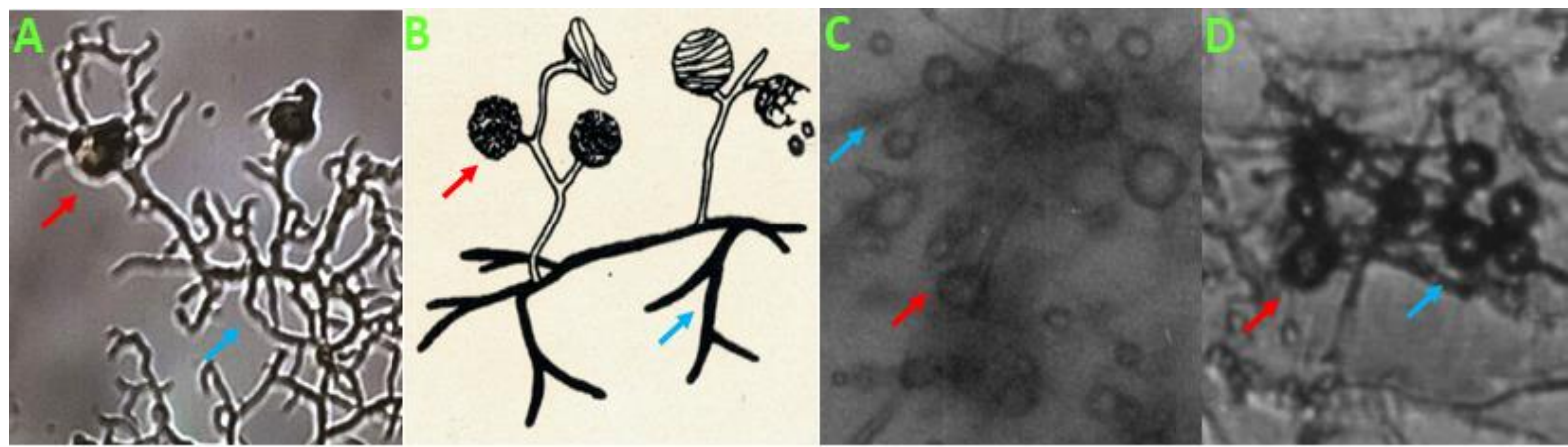

Figure 2. Hyphae (blue arrow) and sporangiospore (red arrow) of SMIP isolate grown on ISPI agar for 21 days at room temperature and observed with 100x magnification. A. SMIP; B. Streptsporangium (Li et al., 2016b); C. Streptosporangium corrugation sp. nov (Williams \& Sharples, 1976); D. Streptosporangium subroserum sp. nov (Zhang et al., 2002).

\section{Antibacterial Activities on Different Media and State Fermentation}

Streptosporangium sp. SMIP was evaluated antibacterial activities in different media and the state fermentations to gain the best media and state fermentations. Streptosporangium sp. SMIP showed antibacterial activities on all of the media and the state fermentations (Table 2). In the SSF, Streptosporangium sp. SMIP cultivated on ISP4 agar medium inhibited more test bacteria than on ISPI agar medium. The results showed that Streptosporangium sp. SMIP cultivated on ISP4 agar exhibited better antibacterial activities than Streptosporangium $\mathrm{sp}$. SMIP cultivated on ISP1 agar (Table 2). Both the media contain different compositions, notably carbon and nitrogen sources. ISPI medium is rich in nitrogen source due to consists of tryptone and yeast extract but very low carbon source. ISP4 medium is deficient in nitrogen and rich carbon that from starch. According to these results, the starch probably played a role in enhancing titer or variation of the antibacterial compounds from Streptosporangium sp. SMIP. Different media that affect the antibacterial activity of microorganisms also are reported by most scientists (Nofiani et al., 2020; Kumar, Duraipandiyan, \& Ignacimuthu, 2014; Benhadi et al., 2019).

Extract Streptosporangium sp. SMIP prepared by the LSF with ISPI broth medium was only active against S. mutant and E. coli (Table 2). The positive control for the well diffusion method was $10 \mu \mathrm{g} /$ well of tetracycline. The results showed that all of the test bacteria was inhibited their growth by tetracycline. The negative control for the well diffusion method was ethyl acetate $(20 \mu \mathrm{L})$ since it was used as a solvent to dissolve Streptosporangium sp. SM 1 P extract. All of the test bacteria was not inhibited growth by ethyl acetate. It could be concluded that ethyl acetate was a safe solvent to dissolve the extract for the antibacterial assay.

Effect of the SSF and the LSF on Streptosporangium sp. SMIP was evaluated by antibacterial activities on ISP1 medium. The result showed slightly different antibacterial activities for both the state fermentations (Table 2). The state fermentation probably changed the secondary metabolites profiles notably having antibacterial activities. The effect of antibacterial activities Nocardia alba FA9 toward the state fermentation is also reported that the SSF is higher the inhibition zone than the LSF but the number of test bacteria that inhibited is the same (Salim, Sharmili, Anbumalarmathi, \& Umamaheswari, 2017). Cephalosporin- $C$ production in the SSF by Acremonium chrysogenum is higher than the LSF (Tabaraie, Ghasemian, Tabaraie, Parvizi, \& Rezazarandi, 2012).

Table 2. Antibacterial activities of Streptosporangium sp. SMIP in different state fermentation and media

\begin{tabular}{|c|c|c|c|c|c|c|}
\hline \multirow{3}{*}{ Test bacteria } & \multirow{3}{*}{$\begin{array}{c}\text { Gram } \\
\text { bacteria }\end{array}$} & \multicolumn{5}{|c|}{ Methods of antibacterial assay } \\
\hline & & \multicolumn{2}{|c|}{$\begin{array}{l}\text { Cross streak method } \\
\text { on medium }\end{array}$} & \multirow{2}{*}{$\begin{array}{c}\text { Dosis } \mu g \\
\text { extract } \\
\text { /well }\end{array}$} & \multicolumn{2}{|c|}{$\begin{array}{l}\text { Diameter of inhibition zone } \\
(\mathrm{mm}) \text { for well diffusion method }\end{array}$} \\
\hline & & ISPI & ISP4 & & ISPI & Tetracycline, $10 \mu \mathrm{g} /$ well \\
\hline S. aureus & Positive & - &,$+ \mathrm{Bs}$ & 750 & - & 3.4 \\
\hline S. mutants & Positive & + , Bs &,$+ \mathrm{Bs}$ & 750 & 1.4 & 15.8 \\
\hline S. typhi & Negative & + , Bs &,$+ \mathrm{Bs}$ & 750 & - & 14.3 \\
\hline E. coli & Negative & - &,$+ \mathrm{Bs}$ & 750 & 2.3 & 14.0 \\
\hline P. aeruginosa & Negative & - & - & 750 & - & 15.7 \\
\hline V. cholerae & Negative & - &,$+ \mathrm{Bs}$ & 750 & - & 12.0 \\
\hline
\end{tabular}




\section{Toxicity Using Brine Shrimp Lethality Test (BSLT)}

The BSLT is a test to evaluate toxicity toward brine shrimp. The extract with high toxicity class based on the BSLT result can be used to indicate that at least one compound in the extract has antitumour, cytotoxic and pesticide activities (Ullah et al., 2013). The standard toxicity of BSLT based on LC 50 value is classified by Meyer, Tanamatayarat, and Clarkson (Meyer et al., 1982; Tanamatayarat, 2016; Meena et al., 2020). The Meyer's toxicity classes are the extracts with LC $_{50}$ $<1000 \mu \mathrm{g} / \mathrm{mL}$ (toxic), and $\mathrm{LC}_{50}>1000 \mu \mathrm{g} / \mathrm{mL}$ (nontoxic) (Meyer et al., 1982). Tanamatayarat's toxicity level are highly toxic $\left(\mathrm{LC}_{50}<10 \mathrm{mg} / \mathrm{mL}\right)$, moderately toxic ( $\left(\mathrm{C}_{50}\right.$ : $\left.10-100 \mathrm{mg} / \mathrm{mL}\right)$, weakly toxic $\left(\mathrm{LC}_{50}: 100\right.$ $1000 \mathrm{mg} / \mathrm{mL})$, and inactive $\left(\mathrm{LC}_{50}>1000 \mathrm{mg} / \mathrm{mL}\right)$ (Tanamatayarat, 2016). Clarkson's classification toxicity is as follows: $\mathrm{LC}_{50}$ above $1000 \mu \mathrm{g} / \mathrm{mL}$ (no toxic), $\mathrm{LC}_{50} 500-1000 \mu \mathrm{g} / \mathrm{mL}$ (low toxic), $\mathrm{LC}_{50} 100$ $500 \mu \mathrm{g} / \mathrm{mL}$ (medium toxic), and $\mathrm{LC}_{50} 0-100 \mu \mathrm{g} / \mathrm{mL}$ (highly toxic) (Meena et al., 2020). The data of this test were analyzed with probit analysis to get a probit model. The probit model of Streptosporangium sp. SMIP extract was $y=0.008 x-0.887$. From this equation was determined $\mathrm{LC}_{50}$ and obtained 106.09 $\mu \mathrm{g} / \mathrm{mL}$. It could be concluded that extract Streptosporangium sp. SMIP was categorized as toxic based on Meyer's classification or weakly toxic based on Tanamatayarat's classification, medium toxic based on Clarkson's classification. $\mathrm{LC}_{50}$ value of ethyl acetate extract Streptosporangium sp. SMIP was higher than that of ethanol extract Streptomyces sp. AJ4 $\left(\mathrm{LC}_{50}\right.$ value $=653.38 \mathrm{\mu g} / \mathrm{mL}$ ) (Rahayu, Fitri, \& Ismail, 2019) but lower than n-butanol extract Streptomyces sp. $\left(\mathrm{LC}_{50}\right.$ value $\left.=42.11 \mu \mathrm{g} / \mathrm{mL}\right)$ (Prashith, Shobha, \& Onkarappa, 2011). The metabolite purified from Streptomyces sp. CAS72 is strong toxicity activity with an $L_{50}$ value $=23.50$ $\mu \mathrm{g} / \mathrm{mL}$ (Palaniappan et al., 2013). However, LC 50 value of ethyl acetate extract Streptosporangium sp. SMIP was promising purified to gain a pure compound.

\section{CONCLUSIONS}

Streptosporangium sp. SMIP, a rare actinobacterium, was successfully isolated from mangrove mud in Mempawah District, West Kalimantan. Streptosporangium sp. SMIP showed antimicrobial and toxicity activities. Secondary metabolite production Streptosporangium sp. SM1P has affected the medium and the state fermentation. Streptosporangium sp. SMIP probably contained more than one secondary metabolites due to having antibacterial and medium toxic activities. Streptosporangium sp. SMIP can be concluded as a potential source to explore bioactive compounds for lead compounds in drug discovery, particularly antibacterial and toxic activities.

\section{ACKNOWLEDGEMENTS}

This study was supported by the Budget Implementation Checklist (DIPA) of Tanjungpura University with the contract number SP. DIPA042.01.2.400955/2019, date 12/05/2018.

\section{REFERENCES}

Arumugam, T., Kumar, S. P., Hemavathy, R. V., Swetha, V., \& Sri, K. R. (2018). Isolation, structure elucidation and anticancer activity from Brevibacillus brevis EGS 9 that combats multi drug resistant actinobacteria. Microbial Pathogenesis, 115, 146-153. https://doi.org/10.1016/i.micpath.2017.12.06 1

Azman, A. S., Othman, I., Velu, S. S., Chan, K. G., \& Lee, L. H. (2015). Mangrove rare actinobacteria: Taxonomy, natural compound, and discovery of bioactivity. Frontiers in Microbiology, 6, 1-15. https://doi.org/10.3389/fmicb.2015.00856

Benhadi, M., Gacemi-Kirane, D., Menasria, T., Guebla, K., \& Ahmane, Z. (2019). Screening of rare actinomycetes isolated from natural wetland ecosystem (Fetzara Lake, Northeastern Algeria) for hydrolytic enzymes and antimicrobial activities. Journal of King Saud University - Science, 37(4), 706-712. https://doi.org/10.1016/i.jksus.2018.03.008

Boonlarppradab, C., Suriyachadkun, C., Supothina, S., \& Laksanacharoen, P. (2016). Amethysione and amethysamide, new metabolites from Streptosporangium amethystogenes BCC 27081. Journal of Antibiotics, 69(6), 459-463. https://doi.org/10.1038/ja.2015.128

Boudjella, H., Bouti, K., Zitouni, A., Mathieu, F., Lebrihi, A., \& Sabaou, N. (2007). Isolation and partial characterization of pigment-like antibiotics produced by a new strain of Streptosporangium isolated from an Algerian soil. Journal of Applied Microbiology, 103(1), 228-236. https://doi.org/10.1111/i.13652672.2006.03280.x

Ding, T., Yang, L. J., Zhang, W. D., \& Shen, Y. H. (2019). The secondary metabolites of rare actinomycetes: Chemistry and bioactivity. RSC Advances, 9(38), 21964-21988. https://doi.org/10.1039/c9ra03579f

Fu, G., Wang, R., Ding, J., Qi, H., Zhao, Z., Chen, C., Zhang, H., Xue, Z., Wang, J., \& Wu, M. (2020). Micromonospora zhangzhouensis sp. nov., a novel actinobacterium isolated from mangrove soil, exerts a cytotoxic activity in vitro. Scientific Reports, 10(1), 1-12. https://doi.org/10.1038/s41598-020-60677-0

Hazarika, S. N., \& Thakur, D. (2020). Actinobacteria. In N. Amaresan, M. Kumar, K. Annapurna, K. 
Kumar, \& A. Sankaranarayanan (Eds.), Beneficial Microbes in Agro-Ecology: Bacteria and Fungi (pp. 443-476). Elsevier Inc. https://doi.org/10.1016/B978-0-12-8234143.00021-6

Jafari, N., Behroozi, R., Farajzadeh, D., Farsi, M., \& Akbari-Noghabi, K. (2014). Antibacterial activity of Pseudonocardia sp. JB05, a rare salty soil actinomycete against Staphylococcus aureus. BioMed Research International, 2014. https://doi.org/10.1155/2014/182945

Kumar, P. S., Duraipandiyan, V., \& Ignacimuthu, S. (2014). Isolation, screening and partial purification of antimicrobial antibiotics from soil Streptomyces sp. SCA 7. Kaohsiung Journal of Medical Sciences, 30(9), 435-446. https://doi.org/10.1016/i.kjms.2014.05.006

Li, Q., Chen, X., Jiang, Y., \& Jiang, C. (2016a). Cultural, Physiological, and Biochemical Identification of Actinobacteria. Actinobacteria Basics and Biotechnological Applications. https://doi.org/10.5772/61462

Li, Q., Chen, X., Jiang, Y., \& Jiang, C. (2016b). Morphological Identification of Actinobacteria. Actinobacteria - Basics and Biotechnological Applications, i. https://doi.org/10.5772/ 61461

Meena, D. K., Sahoo, A. K., Swain, H. S., Borah, S., Srivastava, P. P., Sahu, N. P., \& Das, B. K. (2020). Prospects and perspectives of virtual invitro toxicity studies on herbal extracts of Terminalia arjuna with enhanced stratagem in Artemia salina model: A panacea to explicit the credence of solvent system in brine shrimp lethality bioassay. Emirates Journal of Food and Agriculture, 32(1), 25-37. https://doi.org/10.9755/EJFA.2020.V32.11.2055

Meyer, B. N., Ferrigni, N. A., Putnam, J. E., Jacobsen, L. B., Nichols, D. E., \& Mclaughlin, J. L. (1982). Brine shrimp: A convenient general bioassay for active plant constituents. Journal of Medicinal Plant Research, 45, 31-34.

Mullowney, M. ., Ohainmhire, E., Tanouye, U., Burdette, J. E., Van Pham, C., \& Murphy, B. T. (2015). A pimarane diterpene and cytotoxic angucyclines from a marine-derived Micromonospora sp. in Vietnam's East Sea. Marine Drugs, 13(9), 5815-5827. https://doi.org/10.3390/md13095815

Noël, A., van Soen, G., Rouaud, I., Hitti, E., \& Tomasi, S. (2020). Optimization of cytotoxic activity of Nocardia sp. culture broths using a design of experiments. PLoS ONE, 15(1), 1-14. https://doi.org/10.1371/journal.pone.0227816

Nofiani, R., Weisberg, A. J., Tsunoda, T., Panjaitan, R. G. P., Brilliantoro, R., Chang, J. H., Philmus, B., \& Mahmud, T. (2020). Antibacterial potential of secondary metabolites from Indonesian marine bacterial symbionts. International Journal of
Microbiology, 2020. https://doi.org/10.1155/ 2020/8898631

Palaniappan, S., Panchanathan, M., Packiyarai, V., Kannan, S., Shanmugam, S., Subramaniam, P., Viswanathan, M., Shanmugam, V., \& Balasubramanian, T. (2013). Antibacterial and brine shrimp lethality effect of marine actinobacterium Streptomyces sp. CAS72 against human pathogenic bacteria. Asian Pacific Journal of Tropical Disease, 3(4), 286293. https://doi.org/10.1016/S22221808(13)60071-7

Pfefferle, C., Theobald, U., Gürtler, H., \& Fiedler, H. P. (2000). Improved secondary metabolite production in the genus Streptosporangium by optimization of the fermentation conditions. Journal of Biotechnology, 80(2), 135-142. https://doi.org/10.1016/S01681656(00)00249-2

Prashith, K., Shobha, K., \& Onkarappa, R. (2011). Pancreatic lipase inhibitory and cytotoxic potential of a Streptomyces species isolated from Western Ghat soil, Agumbe, Karnataka, India. International Journal of Pharmaceutical and Biologocal Archives, 2(3), 932-937.

Rahayu, S., Fitri, L., \& Ismail, Y. S. (2019). Short communication: Endophytic actinobacteria isolated from ginger (Zingiber officinale) and its potential as a pancreatic lipase inhibitor and its toxicity. Biodiversitas, 20(5), 1312-1317. https://doi.org/10.13057/biodiv/d200510

Romano, S., Jackson, S. A., Patry, S., \& Dobson, A. D. W. (2018). Extending the "one strain many compounds" (OSMAC) principle to marine microorganisms. Marine Drugs, 16, 244. https://doi.org/10.3390/md16070244

Salim, F. M., Sharmili, S. A., Anbumalarmathi, J., \& Umamaheswari, K. (2017). Isolation, molecular characterization and identification of antibiotic producing actinomycetes from soil samples. Journal of Applied Pharmaceutical Science, 7(9), 69-75. https://doi.org/10.7324/ JAPS. 2017.70909

Salwan, R., \& Sharma, V. (2020). Molecular and biotechnological aspects of secondary metabolites in actinobacteria. Microbiological Research, 231, 126374. https://doi.org/10.1016/j.micres.2019.126374

Sharma, Poonam, Arpit, T., Bharat, B., Bhasin, S., \& Modi, H. A. (2018). Approach towards different fermentative techniques for the production of bioactive actinobacterial melanin. Beni-Suef University Journal of Basic and Applied Sciences, 7(4), 695-700. https://doi.org/10.1016/i.bjbas.2018.08.002

Sharma, Priyanka, Kalita, M. C., \& Thakur, D. (2016). Broad spectrum antimicrobial activity of forestderived soil actinomycete, Nocardia sp. PB-52. Frontiers in Microbiology, 7, 1-17. 
https://doi.org/10.3389/fmicb.2016.00347

Tabaraie, B., Ghasemian, E., Tabaraie, T., Parvizi, E., \& Rezazarandi, M. (2012). comparative evalution of cephalosporin- $C$ production in solid. Journal of Microbiology, Biotechnology, and Food Sciences, 2(1), 83-94.

Tanamatayarat, P. (2016). Antityrosinase, antioxidative activities, and brine shrimp lethality of ethanolic extracts from Protium serratum (Wall. ex Colebr.) Engl. Asian Pacific Journal of Tropical Biomedicine, 6(12), 1050 1055.

https://doi.org/10.1016/i.apjtb.2016.10.001

Ullah, M. O., Haque, M., Urmi, K. F., Abu, A. H., Anita, E. S., Begum, M., \& Hamid, K. (2013). Anti-bacterial activity and brine shrimp lethality bioassay of methanolic extracts of fourteen different edible vegetables from Bangladesh. Asian Pacific Journal of Tropical Biomedicine, 3(1), 1-7. https://doi.org/10.1016/S2221 1691(13)60015-5

Wietz, M., Månsson, M., \& Gram, L. (2011). Chitin stimulates production of the antibiotic andrimid in a Vibrio coralliilyticus strain. Environmental Microbiology Reports, 3(5), 559-564. https://doi.org/10.1111/j.17582229.2011.00259.x

Williams, S. T., \& Sharples, G. P. (1976). Streptosporangium corrugation sp. nov., an actinomycete with some unusual morphological features. International Journal of Systematic Bacteriology, 26(1), 45-52. https://doi.org/10.1099/00207713-26-1-45

Williston, E. H., Zia-Walrath, P., \& Youmans, G. P. (1947). Plate methods for testing antibiotic activity of actinomycetes against virulent human type tubercle bacilli. Journal of Bacteriology, 54(5), 563-568. https://doi.org/10.1128/ib.54.5.563568. 1947

Zhang, L., Jiang, C., \& Chen, W. (2002). Actinomycete with an unusual phospholipid pattern. International Journal of Systematic and Evolutionary Microbiology, 52, 1235-1238. 